Article

\title{
Trans-Resveratrol Supplementation and Endothelial Function during the Fasting and Postprandial Phase: A Randomized Placebo-Controlled Trial in Overweight and Slightly Obese Participants
}

\author{
Sanne M. van der Made ${ }^{1,2}$, Jogchum Plat ${ }^{1}$ and Ronald P. Mensink ${ }^{1,2, *}$ \\ 1 Department of Human Biology, NUTRIM School of Nutrition and Translational Research in Metabolism, \\ Maastricht University Medical Center, 6200 MD Maastricht, The Netherlands; \\ sanne.vandermade@maastrichtuniversity.nl (S.M.v.d.M.); j.plat@maastrichtuniversity.nl (J.P.) \\ 2 Top Institute Food and Nutrition (TIFN), 6700 AN Wageningen, The Netherlands \\ * Correspondence: r.mensink@maastrichtuniversity.nl; Tel.: +31-43-3881308
}

Received: 22 March 2017; Accepted: 8 June 2017; Published: 12 June 2017

\begin{abstract}
Studies on the effects of the long-term intake of trans-resveratrol on vascular function are conflicting. In addition, postprandial effects of long-term trans-resveratrol intake on endothelial function are not known. We therefore supplemented 45 overweight and slightly obese volunteers (25 men and 20 women) with a mean $( \pm S D)$ age of $61 \pm 7$ years and body mass index of $28.3 \pm 3.2 \mathrm{~kg} / \mathrm{m}^{2}$ in random order trans-resveratrol $(2 \times 75 \mathrm{mg} /$ day $)$ or placebo capsules for 4 weeks, separated by a washout period of at least 4 weeks. At the end of each intervention period, brachial artery flow-mediated vasodilation (FMD) was measured before and after meal consumption. Plasma biomarkers for endothelial function, inflammation, and glucose and lipid metabolism were also determined. Compared with the placebo, trans-resveratrol did not affect fasting FMD $(2.9 \pm 1.4 \%$ vs. $3.0 \pm 1.9 \% ; p=0.69)$. After the postprandial test, changes in FMD $(-0.7 \pm 2.3 \%$ vs. $0.2 \pm 2.6 \% ; p=0.13)$ were also not significantly different. Postprandial changes in biomarkers were also comparable. In conclusion, for overweight and slightly obese volunteers, a daily intake of $150 \mathrm{mg}$ of trans-resveratrol for 4 weeks does not change plasma biomarkers of endothelial function or inflammation in the fasting state or postprandial phase.
\end{abstract}

Keywords: flow-mediated vasodilation; vascular function; trans-resveratrol; postprandial; humans

\section{Introduction}

Resveratrol, a plant polyphenolic compound, found for example in the skin of black grapes, may reduce the risk of coronary heart diseases and diabetes [1]. However, earlier we have reported that a daily supplement of $150 \mathrm{mg}$ of trans-resveratrol, the active isomer of resveratrol, for 4 weeks did not improve fasting metabolic risk markers in overweight and slightly obese men and women [2]. This result is in accordance with several other human studies also not observing effects of resveratrol supplementation on fasting lipid and glucose concentrations [3]. Further, a study on type 2 diabetic individuals did not find an effect on postprandial glucose concentrations [4]. Nevertheless, trans-resveratrol might affect other parameters related to cardiovascular health, such as vascular endothelial dysfunction.

In vitro evidence for beneficial effects of resveratrol on endothelial function was provided by Wallerath and colleagues [5], who demonstrated that in human umbilical vein endothelial cells (HUVECs), resveratrol up-regulated endothelial nitrogen oxide synthase (eNOS) mRNA and protein expressions, as well as nitrogen oxide (NO) production, in a time- and concentration-dependent manner. NO plays an essential role in the maintenance of vascular tone and reactivity. A later study with HUVECs using more physiologically relevant concentrations suggested that other factors also 
contribute to the positive effects of resveratrol on endothelial function, such as sirtuin 1 (SIRT1) up-regulation and cyclooxygenase 1 (COX-1) inhibition [6].

In humans, endothelial function can be assessed non-invasively by flow-mediated dilation (FMD) [7]. Wong et al. [8] have reported that the acute intake of 30,90 or $270 \mathrm{mg}$ of trans-resveratrol dose-dependently improved FMD in overweight and obese adults with elevated blood pressure. Obese, but otherwise healthy adults, also showed an improvement in FMD after a daily intake of $75 \mathrm{mg}$ of trans-resveratrol for 6 weeks [9]. However, in another study, no effect on FMD was observed in 40 post-infarction patients after the intake of $10 \mathrm{mg}$ of trans-resveratrol daily for 3 months [10]. In addition, the effects of long-term trans-resveratrol intake on endothelial function during the postprandial phase have not been studied. A high-fat dietary challenge may negatively influence FMD, possibly through increasing the inflammatory response and oxidative stress, which may reduce endothelial function [11-14]. Such a dietary challenge can therefore be used to evaluate subtle changes in endothelial function following long-term trans-resveratrol intake. Therefore, the main objective of the present study was to examine the effects of a daily intake of $150 \mathrm{mg}$ trans-resveratrol supplementation for 4 weeks on endothelial function in the fasting state and postprandial phase in overweight and slightly obese participants.

\section{Materials and Methods}

\subsection{Participants and Study Design}

Overweight (body mass index, BMI, $\mathrm{kg} / \mathrm{m}^{2}: 25-30$ ) and obese (BMI: 30-35), healthy participants aged between 45 and 70 years (mean \pm SD: $61 \pm 7$ years) participated in a double-blind, randomized, placebo-controlled, cross-over study. Inclusion and exclusion criteria have been described previously [2]. Briefly, all participants were apparently healthy and did not suffer from disturbances in lipid or glucose metabolism, nor cardiovascular diseases. The inclusion criterion for serum HDL cholesterol concentrations was $<1.21 \mathrm{mmol} / \mathrm{L}$ for men and $<1.53 \mathrm{mmol} / \mathrm{L}$ for women, as the primary aim of the study was to examine the effects of trans-resveratrol supplementation on serum apoA-I concentrations. These cut-off values were the mean values found in the PROCAM study [15]. Participants were informed about the aim of the study and nature and risk of the experimental procedures before written informed consent was obtained. This study was conducted according to the guidelines laid down in the Declaration of Helsinki as revised in 1983, approved by the Ethics Committee of the Maastricht University Medical Centre, and registered on 17 January 2011, at ClinicalTrials.gov with the number NCT01364961. One hundred and eight participants were screened for eligibility, of which 58 did not meet the inclusion criteria. Thus, 50 participants started the study.

Subjects started the 4-week intervention with either trans-resveratrol $(2 \times 75 \mathrm{mg} /$ day; resVida, $99.9 \%$ trans-resveratrol $)$ or placebo $(2 \times 58 \mathrm{mg} /$ day cellulose $)$ capsules. At the start, subjects received more capsules than they needed for the entire period to account for unforeseen losses. They were instructed to take one capsule at lunch and another capsule at dinner. After a washout period of at least 4 weeks, regimens were crossed over. All capsules were provided by DSM Nutritional Products Ltd. (Kaiseraugust, Switzerland).

Subjects were weighed at each visit (days 0,25 and 28 of each period). On day 28, a postprandial test started in the morning after a $12 \mathrm{~h}$ overnight fast. Participants were asked to refrain from any strenuous physical exercise and to not consume alcohol on the day before testing. Before and $240 \mathrm{~min}$ after a meal intake, FMD and arterial stiffness were measured. After the fasting vascular measurements, an intravenous cannula (Becton, Dickinson and Company, Franklin Lanes, NY, USA) was inserted into an antecubital vein, and a fasting blood sample (T0) was collected. Participants were then asked to consume a test meal within $10 \mathrm{~min}$. Subsequent blood samples were drawn 15 (T15), 30 (T30), 45 (T45), 60 (T60), 90 (T90), 120 (T120), 180 (T180) and 240 (T240) min after meal consumption. Participants were allowed to drink water at their convenience throughout the postprandial test. 


\subsection{Test Meal}

During each postprandial test, participants received two muffins and $300 \mathrm{~mL}$ of skim milk ( $0 \%$ vet Melkdrank, Friesland-Campina, Friesland, The Netherlands). The meal provided 4598 kJ, $26.5 \mathrm{~g}$ of protein, $121 \mathrm{~g}$ of carbohydrates and $56.6 \mathrm{~g}$ of fat (Table S1; protein/carbohydrate/fat: $9.6 \%$ of energy $/ 44.6 \%$ of energy $/ 46.6 \%$ of energy). One batch of muffins was prepared for the entire study and stored at $-20{ }^{\circ} \mathrm{C}$ until consumption.

\subsection{Flow-Mediated Dilation and Arterial Stiffness}

FMD of the brachial artery, a measure of endothelium-dependent vascular reactivity, was measured after at least $15 \mathrm{~min}$ of supine rest, as described [7]. The same trained and blinded ultrasonographer performed all measurements. For 29 participants, all FMD measurements were made with a high-resolution ultrasound system using a 3-11 MHz wide-band linear array transducer (Philips Sonos 5500 system; Philips Ultrasound, Andover, MA, USA). For 14 participants, all FMD measurements were performed with a 5-10 MHz linear array probe (Picus I, Esaote Biomedica, Genoa, Italy). Images of the brachial artery were taken longitudinally, $2-10 \mathrm{~cm}$ above the antecubital fossa in combined Doppler/brightness mode (B-mode). A probe holder was used to secure the position of the transducer during the measurement. After a 3-min baseline measurement, a peripherally hypoxic state was induced by inflation of a pneumatic tourniquet (Hokanson TD312 automatic cuff inflator, D.E. Hokanson, Inc., Bellevue, WA, USA) placed around the forearm, inflated to a pressure of at least $50 \mathrm{mmHg}$ above systolic pressure, with a minimal pressure of $200 \mathrm{mmHg}$. After $5 \mathrm{~min}$, the cuff was deflated, resulting in reactive hyperemia, which was recorded for another $5 \mathrm{~min}$. Images were continuously recorded on DVD during the entire 13-min measurement protocol. Acquired images were analyzed using an in-house developed, semi-automated image-analysis algorithm (Prof. A.P. Hoeks, Department of Biomedical Engineering, Maastricht University Medical Center, Maastricht, The Netherlands). FMD responses were expressed as the percentage increase in brachial artery diameter from baseline to maximal dilation post-occlusion.

Arterial stiffness was assessed by carotid-femoral pulse wave velocity $\left(\mathrm{PWV}_{\mathrm{cf}}\right)$ measurements (SphygmoCor CPV System, AtCor Medical Pty. Ltd., West Ryde, Australia), as described [16]. Measurements were made after at least $30 \mathrm{~min}$ of supine rest. An automated sphygmomanometer (Mobilograph NG, IEM GmbH, Stolberg, Germany) was used to measure supine blood pressure. Peripheral and central augmentation indexes ( $\mathrm{Aix}_{\mathrm{p}}$ and $\mathrm{Aix}_{\mathrm{c}}$, respectively) were measured at the radial site by tonometry (SphygmoCor CPV System, AtCor Medical Pty. Ltd., West Ryde, Australia), as described [17].

FMD and arterial stiffness measurements were performed in a quiet, temperature-controlled, darkened room at baseline and $4 \mathrm{~h}$ postprandially (day 28 of each 4 -week period).

\subsection{Blood Analyses}

Blood was sampled in ethylene diamine tetraacetic acid (EDTA)-containing, sodium fluoride (NaF)-containing, and serum separator tubes (Becton, Dickinson and Company, Franklin Lanes, NY, USA). Blood drawn into serum separator tubes was allowed to clot for at least $30 \mathrm{~min}$ at $21^{\circ} \mathrm{C}$, and was followed by centrifugation at $1300 \times g$ for $15 \mathrm{~min}$ at $21^{\circ} \mathrm{C}$. EDTA- and NaF-containing tubes were immediately placed on ice after blood drawing. Tubes were centrifuged at $1300 \times \mathrm{g}$ for $15 \mathrm{~min}$ at $4{ }^{\circ} \mathrm{C}$. Plasma and serum aliquots were directly snap-frozen in liquid nitrogen and stored at $-80^{\circ} \mathrm{C}$ until analysis.

Plasma glucose concentrations were measured in NaF plasma for T0, T15, T30, T45, T60, T90, T120 and T240 (Horiba ABX, Montpellier, France). Concentrations of triacylglycerol, corrected for free glycerol, were determined in serum samples from T0, T60, T120, T180 and T240 (GPO Trinder; Sigma Diagnostics, Santa Clara, CA, USA). Insulin concentrations were measured in EDTA plasma for T0, 15, 30, 45, 60, 90, 120, 180 and 240 (RIA; Millipore, Billerica, MA, USA). Interleukin 6 (IL-6), tumor necrosis factor alpha (TNF $\alpha)$, soluble endothelial selectin (sE-selectin), soluble thrombomodulin (sTM), soluble platelet selectin (sP-selectin), soluble intercellular adhesion molecule-1 (sICAM-3), soluble intercellular 
adhesion molecule-1 (sICAM-1), and soluble vascular adhesion molecule-1 (sVCAM-1) were measured in EDTA plasma for T0, 120 and 240 by commercially available Multi Spot ELISA kits (Meso Scale Discovery, Rockville, MD, USA).

\subsection{Statistical Analyses}

Data are presented as means \pm standard deviation (SD), unless otherwise indicated. Results obtained during the fasting state at the end of the trans-resveratrol and placebo periods, as well as changes within a group, were compared using a paired $t$-test. For plasma glucose, plasma insulin and serum triacylglycerol, the area under the curve (AUC) and the incremental area under the curve (iAUC) were calculated using the trapezoidal rule [18]. Maximal changes in concentrations were calculated by subtracting baseline values from maximal or minimal values. Differences in AUC, iAUC and maximal changes between the test periods were tested for significance by a paired $t$-test.

Changes over time for plasma glucose, plasma insulin, serum triacylglycerol, plasma sE-selectin, plasma sICAM-1, plasma sICAM-3, plasma sP-selectin, plasma sTM, plasma sVCAM-1, plasma IL-6, and plasma TNF $\alpha$ were tested by linear mixed models, with "meal" and "time" as fixed factors and "meal $\times$ time" as the interaction term. If the interaction term reached statistical significance, differences in responses between the meals were compared at each individual time point using a Bonferroni correction. If the interaction term was not statistically significant, it was omitted from the model. If, in that model, the factor time was significant, post hoc tests with Bonferroni correction were carried out to compare concentrations at the different time points to baseline concentrations.

For FMD and $\mathrm{PWV}_{\mathrm{cf}}$, changes between fasting and postprandial values were calculated. Differences between the two test periods were evaluated for fasting measurements and postprandial changes by a student's paired $t$-test. Post hoc exploratory data analyses were performed to examine whether the results depended on sex, degree of obesity, or the use of prescribed medication. Carry-over effects of these responses, which were absent, were analyzed as described [19]. Results were considered to be statistically significant if $p \leq 0.05$. Statistical analyses were performed using SPSS 19.0 for Mac OS X (SPSS Inc., Chicago, IL, USA).

\section{Results}

\subsection{Study Participants}

The flow of participants and their baseline characteristics have been presented before [2] and are shown in Figure S1 and Table S2. Forty-five participants finished the study. Due to technical problems, FMD measurements could not be performed for two participants on one test-day. For six participants, one measurement could not be interpreted. Therefore, FMD results are presented for 37 participants. Compliance to the treatments was confirmed by increases in fasting plasma total (aglycone and glucuronide conjugates) resveratrol and total dihydroresveratrol [2]. From the number of returned capsules, it was estimated that 99\% (range: 88-111\%) of the provided capsules were used on average. BMIs at the start and at the end of the placebo period were $28.4 \pm 3.1 \mathrm{~kg} / \mathrm{m}^{2}$ and $28.3 \pm 3.1 \mathrm{~kg} / \mathrm{m}^{2}$, respectively. For the trans-resveratrol period, these values were $28.3 \pm 3.0 \mathrm{~kg} / \mathrm{m}^{2}$ and $28.4 \pm 3.1 \mathrm{~kg} / \mathrm{m}^{2}$. Changes within or between treatment periods were not significantly different.

\subsection{Vascular Function Measurements}

Fasting FMD values at the end of the placebo and trans-resveratrol periods were not significantly different. In addition, changes in FMD after meal intakes were not different between both interventions (Table 1). Within the placebo group, we also did not observe an effect of the meal challenge on FMD. Comparing trans-resveratrol and the placebo, no differences were found between fasting arterial diameters or differences in postprandial changes. Furthermore, measures of arterial stiffness, $\mathrm{PWV}_{\mathrm{cf}}$, $\mathrm{AIx}_{\mathrm{p}}, \mathrm{AIx}_{\mathrm{c}}$ and $\mathrm{AIx}_{\mathrm{c}}$ adjusted for a heart rate of 75 beats per minute $\left(\mathrm{AIx}_{\mathrm{c}} \mathrm{HR} 75\right)$, were not affected by trans-resveratrol intake. 
Table 1. Effects in overweight and slightly obese men and women of 4-week trans-resveratrol supplementation (150 mg daily) on FMD and arterial stiffness before and after a test meal.

\begin{tabular}{|c|c|c|c|c|c|c|c|c|}
\hline & \multicolumn{3}{|c|}{ Placebo } & \multicolumn{3}{|c|}{ Resveratrol } & \multirow{2}{*}{$p_{\text {fasting }}$} & \multirow{2}{*}{$p_{\text {change }}$} \\
\hline & Fasting & $4 \mathrm{~h}$ after Meal Intake & Change after Meal Intake & Fasting & $4 \mathrm{~h}$ after Meal Intake & Change after Meal Intake & & \\
\hline FMD (\%) & $3.0 \pm 1.9$ & $3.3 \pm 2.5$ & $0.2 \pm 2.6$ & $2.9 \pm 1.4$ & $2.2 \pm 2$ & $-0.7 \pm 2.3$ & 0.69 & 0.13 \\
\hline Baseline diameter $(\mathrm{mm})$ & $4.4 \pm 0.8$ & $4.3 \pm 0.9$ & $-0.1 \pm 0.3$ & $4.3 \pm 0.8$ & $4.3 \pm 0.9$ & $-0.1 \pm 0.4$ & 0.15 & 0.73 \\
\hline $\operatorname{AIx}_{\mathrm{c}}(\%)$ & $32 \pm 10$ & $31 \pm 7$ & $-1 \pm 7$ & $32 \pm 10$ & $30 \pm 9$ & $-2 \pm 6$ & 0.79 & 0.59 \\
\hline $\operatorname{AIx}_{\mathrm{c}} \mathrm{HR} 75(\%)$ & $24 \pm 8$ & $23 \pm 8$ & $-1 \pm 5$ & $25 \pm 9$ & $23 \pm 8$ & $-2 \pm 6$ & 0.46 & 0.62 \\
\hline $\operatorname{AIx}_{p}(\%)$ & $89 \pm 13$ & $86 \pm 11$ & $-3 \pm 7$ & $92 \pm 17$ & $89 \pm 15$ & $-3 \pm 14$ & 0.29 & 0.97 \\
\hline $\operatorname{PWV}_{\mathrm{cf}}(m / s)$ & $10.4 \pm 2.7$ & $10.9 \pm 1.8$ & $0.4 \pm 2.6$ & $11.0 \pm 3.4$ & $10.5 \pm 3.1$ & $-0.7 \pm 2.7$ & 0.16 & 0.09 \\
\hline
\end{tabular}

Values are means $\pm \mathrm{SD} ; n=45$, except for FMD $(n=37)$, baseline diameter $(n=37)$ and $\mathrm{PWV}_{\mathrm{cf}}(n=40)$. FMD, flow-mediated vasodilation; $\mathrm{AIx}_{\mathrm{c}}$, central augmentation index; $\mathrm{AIx}_{\mathrm{c}} \mathrm{HR}_{75}$, central augmentation index adjusted for a heart rate of 75 beats per minute; $\mathrm{AIx}_{\mathrm{p}}$, peripheral augmentation index; $\mathrm{PWV}_{\mathrm{cf}}$, carotid-femoral pulse wave velocity. Fasting values $\left(p_{\text {fasting }}\right)$ and changes after meal intake $\left(p_{\text {change }}\right)$ during the trans-resveratrol period were compared with values obtained during the placebo period. 


\subsection{Postprandial Glycaemia and Lipaemia}

Fasting concentrations of plasma glucose, plasma insulin, and serum triacylglycerol did not differ between the test days at the end of the placebo and trans-resveratrol periods. After meal consumption, plasma glucose and plasma insulin concentrations significantly increased $(p<0.001$ for time effect; Figure 1). These increases, however, were not significantly different between the two intervention periods. Serum triacylglycerol concentrations also increased significantly after the meal $(p<0.001$ for time effect), but these effects were not changed by resveratrol supplementation. The iAUCs, AUCs and maximal changes in these parameters were also comparable between the two intervention periods (Table 2).
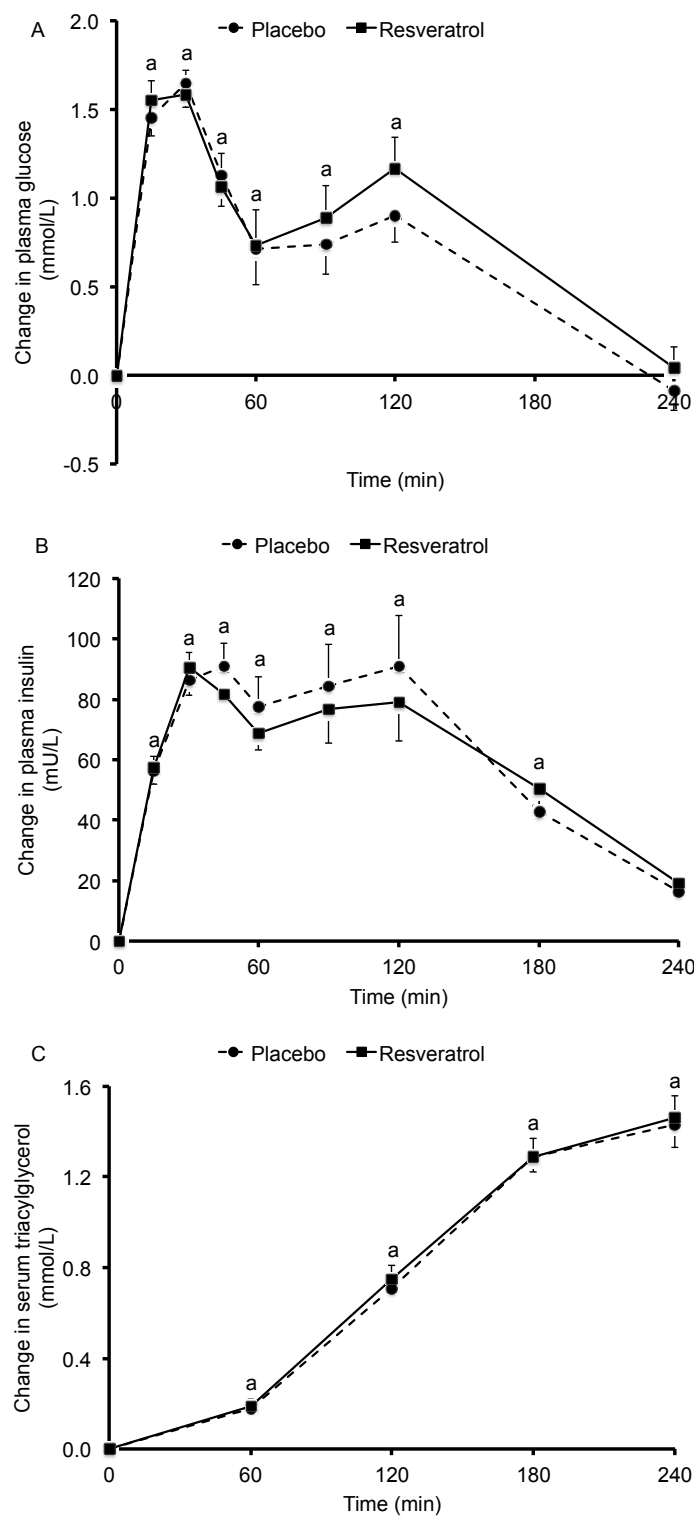

Figure 1. Baseline-corrected changes in plasma glucose (A), plasma insulin (B) and serum triacylglycerol (C) concentrations in 45 overweight and slightly obese men and women after consumption of two muffins and $300 \mathrm{~mL}$ of skim milk following a 4-week placebo period or a 4-week trans-resveratrol (150 $\mathrm{mg}$ daily) period. Values are means \pm SEM. ${ }^{\text {a }}$ Significant change from baseline; $p<0.05$. 
Table 2. Effects in overweight and slightly obese men and women of 4-week trans-resveratrol supplementation (150 mg daily) on postprandial glucose, insulin and triacylglycerol metabolism.

\begin{tabular}{lccc}
\hline & Placebo & Resveratrol & $p$-Value \\
\hline Plasma glucose & & & \\
iAUC (mmol·min/L) & $187 \pm 136$ & $195 \pm 147$ & 0.59 \\
AUC (mmol·min/L) & $1421 \pm 207$ & $1421 \pm 224$ & 1.00 \\
Maximal change (mmol/L) & $2.08 \pm 0.87$ & $2.15 \pm 0.79$ & 0.48 \\
Plasma insulin & & & \\
iAUC (U.min/L) & $11.2 \pm 11.0$ & $10.5 \pm 10.0$ & 0.34 \\
AUC (U·min/L) & $13.5 \pm 11.4$ & $12.9 \pm 10.4$ & 0.34 \\
Maximal change (mU/L) & $131 \pm 117$ & $125 \pm 95$ & 0.43 \\
Serum triacylglycerol & & & \\
iAUC (mmol·min/L) & $169 \pm 68$ & $176 \pm 74$ & 0.32 \\
AUC (mmol·min/L) & $541 \pm 203$ & $566 \pm 218$ & 0.54 \\
Maximal change (mmol/L) & $1.49 \pm 0.59$ & $1.49 \pm 0.62$ & 0.94 \\
\hline
\end{tabular}

Values are means $\pm \mathrm{SD}, n=45$. iAUC, incremental area under the curve; AUC, area under the curve.

\subsection{Postprandial Markers of Endothelial Activation and Inflammation}

Fasting concentrations of plasma markers for endothelial activation (sE-selectin, sICAM-1, sICAM-3, sP-selectin, sTM, sVCAM-1) and inflammation (IL-6, TNF $\alpha$ ) were comparable between both intervention periods. No significant meal $x$ time interactions were found, except for plasma sICAM-1 $(p=0.02)$. For T120, plasma sICAM-1 concentrations were higher after consuming trans-resveratrol $(p=0.04)$. For all other plasma markers, time effects were significant $(p<0.001$; Figure 2$)$.
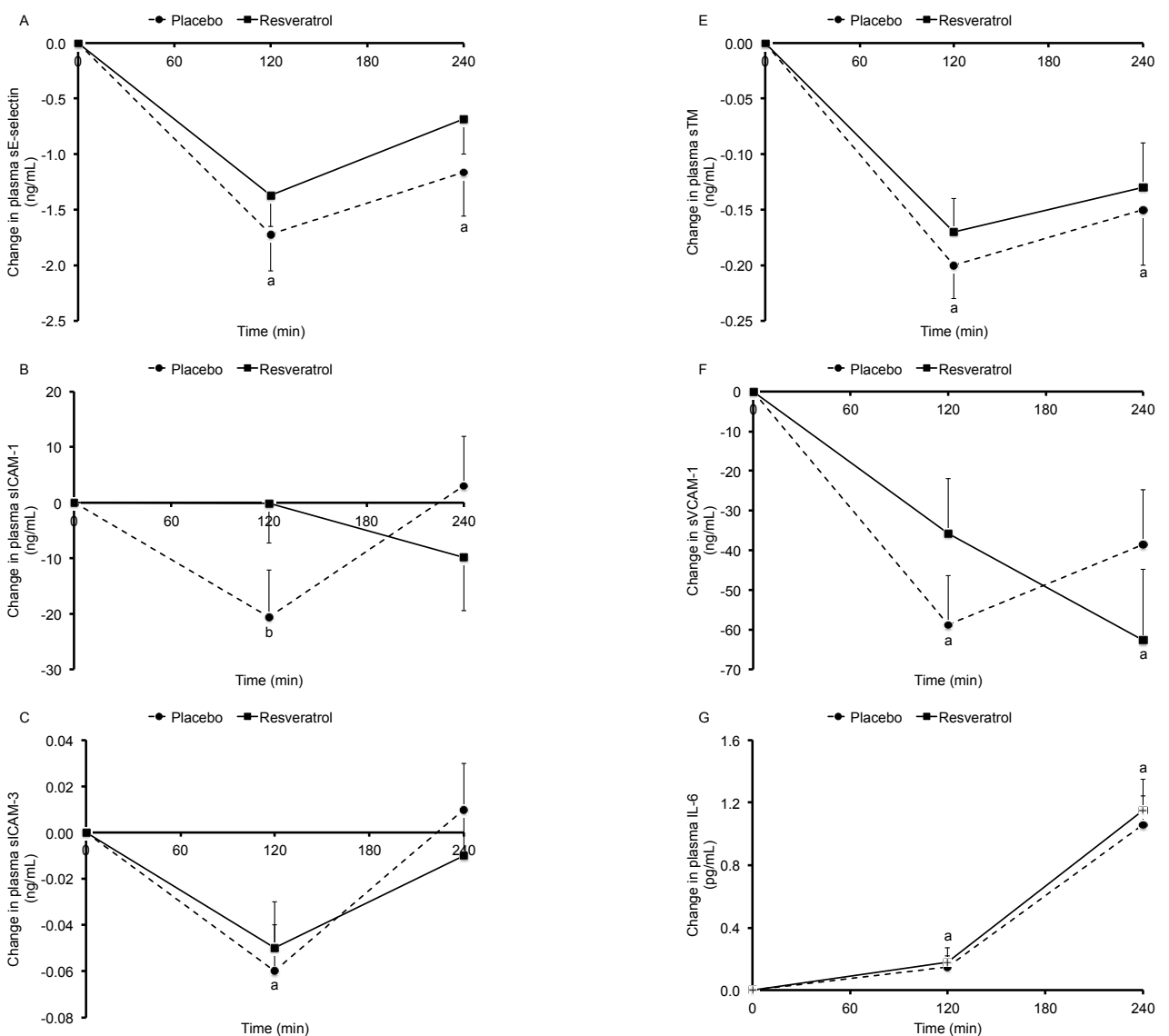

Figure 2. Cont. 

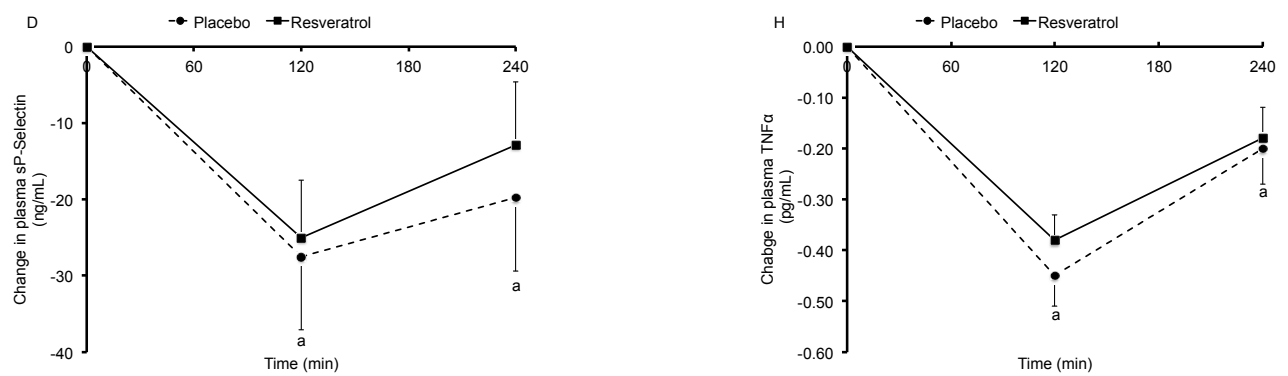

Figure 2. Baseline-corrected changes in plasma sE-selectin (A), sICAM-1 (B), sICAM-3 (C), sP-selectin (D), sTM (E), sVCAM-1 (F), IL-6 (G), and TNF $\alpha(\mathbf{H})$ concentrations in 45 overweight and slightly obese men and women after consumption of two muffins and $300 \mathrm{~mL}$ of skim milk following a 4-week placebo period or a 4-week trans-resveratrol (150 mg daily) period. Values are means \pm SEM; sE-selectin: soluble endothelial selectin; sICAM-1: soluble intercellular adhesion molecule-1; sICAM-3: soluble intercellular adhesion molecule-3; sP-selectin: soluble platelet selectin; sTM: soluble thrombomodulin; sVCAM-1: soluble vascular cell adhesion molecule-1; IL-6: interleukin 6; TNF $\alpha$ : tumor necrosis factor alpha. ${ }^{\text {a }}$ Significant change from baseline; $p<0.05$. ${ }^{\mathrm{b}}$ Changes between the trans-resveratrol and placebo periods significantly different; $p<0.05$.

\subsection{Exploratory Data Analyses}

Exploratory data analyses did not suggest that effects were dependent upon sex (25 men vs. 20 women) or degree of obesity (BMI $\geq 30 \mathrm{~kg} / \mathrm{m}^{2} ; n=16,7$ men and 9 women vs. BMI $<30 \mathrm{~kg} / \mathrm{m}^{2}$; $n=29,18$ men and 11 women). When analyses were restricted to participants that did not use any prescribed medication $(n=31)$, conclusions were comparable as well.

\section{Discussion}

In this study on overweight and slightly obese men and women, a daily trans-resveratrol supplement of $150 \mathrm{mg}$ for 4 weeks did not affect FMD, arterial stiffness plasma, or markers of endothelial function and low-grade inflammation in the fasting state or the postprandial phase.

In vitro and animal studies have suggested positive effects of resveratrol on endothelial function, possibly through effects on eNOS, NO bioavailability, SIRT1, and COX-1 [5,6,20,21]. However, in vivo resveratrol undergoes fast and extensive metabolic conversion, leading in humans to low plasma concentrations of resveratrol, but high concentrations of resveratrol metabolites, such as dihydroresveratrol monoglucuronide [22]. In the present study, we also found that fasting plasma dihydroresveratrol concentrations were about twice as high as those for resveratrol [2].

In humans, positive effects of trans-resveratrol supplementation on endothelial function have also been reported. In an acute study of 19 overweight and obese adults with elevated blood pressure, Wong et al. observed a dose-dependent effect of trans-resveratrol intake $(0,30,90,270 \mathrm{mg})$ on FMD [8]. Additionally, a daily supplement of $75 \mathrm{mg}$ trans-resveratrol for 6 weeks increased FMD by 1.38 percent points from $5.83 \%$ (placebo) to $7.21 \%$ in 28 obese, but otherwise healthy adults (BMI $30-45 \mathrm{~kg} / \mathrm{m}^{2}$ ) [9]. However, we found no effects on FMD of trans-resveratrol supplementation. In retrospect, the statistical power of our study was $>95 \%$ to detect a true change in FMD of 1.38 percent points with an alpha of 0.05 . Thus, our study was adequately powered to detect the effect observed by Wong et al. [9]. The reason for this discrepant finding is not clear. Our participants had a lower BMI, but exploratory subgroup analyses did not indicate an effect on FMD in the obese participants. It should be noted, however, that the statistical power for subgroup analyses might not have been sufficient. It is also possible that the duration of our study was not long enough, as the study by Wong et al. [9] lasted 6 weeks. Finally, FMD values in our study were lower than those measured by Wong et al. [9], although it is difficult to compare absolute FMD values between study sites due to different methodologies. It can be speculated that the endothelial function of our participants may have been too poor and was 
therefore not responsive to diet-induced changes within a 4-week period. On the other hand, it can be argued that a lower FMD would present more tendency to change or improve. Thus, an obvious reason to explain the difference in findings between our study and the study of Wong et al. is lacking [9]. A multicenter study using rigidly standardized measurements and addressing different aspects of endothelial function may be needed to increase the external validity of findings and to further clarify the effects of trans-resveratrol on the vasculature.

Participants also received a meal to assess the effect of $150 \mathrm{mg}$ of trans-resveratrol on the postprandial FMD response. To disentangle the effects of long-term trans-resveratrol supplementation from those of an acute intake, we deliberately chose not to incorporate trans-resveratrol in the meal challenge. However, trans-resveratrol did not modify the postprandial change in FMD, even though the expected increase in serum triacylglycerol concentrations, which may deteriorate the postprandial FMD response, was observed [23]. Unexpectedly, FMD did not change at all during the postprandial period. Earlier, we have shown an impaired FMD $2 \mathrm{~h}$ after consuming a high-fat meal for overweight and slightly obese men [17]. The main difference between the two studies was the amount of protein in the test meal, which was lower in the latter study [17]. Indeed, a postprandial impairment in FMD of the brachial artery was not observed, when caseinate proteins were added to the mixed meal [24], which was explained by an increased supply of the amino acid L-arginine, a precursor for NO synthesis. Another explanation may be that in the present study, FMD was measured $4 \mathrm{~h}$ after meal intake, as opposed to $2 \mathrm{~h}$ in the earlier study. However, other studies did show a 4-hour postprandial deterioration in FMD after a high-fat meal [25,26]. As trans-resveratrol did not change postprandial plasma glucose, plasma insulin, or serum triacylglycerol concentrations, the absence of effects on FMD between the treatments was not confounded by differences in these blood parameters.

Trans-resveratrol supplementation did also not affect $\mathrm{PWV}_{\mathrm{cf}}$ and pulse wave analyses in the fasting state or the postprandial phase. Wong et al. [9] also found no effects of trans-resveratrol on arterial compliance in their 6-week trial. To the best of our knowledge, no other studies assessed the effect of pure resveratrol on $\mathrm{PWV}_{\mathrm{cf}}$. However, 4 weeks of pomegranate juice supplementation, a source of resveratrol, also had no effect on $\mathrm{PWV}_{\mathrm{cf}}$ [27]. Dark chocolate, however, which is rich in flavanols, improved fasting $\mathrm{PWV}_{\mathrm{cf}}$ within 4 weeks, while blood pressure did not change [28]. This suggests that the timeframe chosen in our study was not too short to demonstrate changes in $\mathrm{PWV}_{\mathrm{cf}}$.

Anti-inflammatory effects of resveratrol have also been reported. In vitro, treating aortic endothelial cells treated with resveratrol at physiologically relevant concentrations inhibited TNF $\alpha$ induced NF- $\kappa$ B activity [29], reduced inflammatory gene expression [30], and decreased monocyte adhesiveness to the endothelium [31]. Additionally, when cultured human coronary artery endothelial cells were incubated with plasma from patients that had received $400 \mathrm{mg}$ of trans-resveratrol for 4 weeks, inflammatory gene expression was inhibited [32]. In vivo, TNF $\alpha$ concentrations were lower after supplementation for 30 days with $150 \mathrm{mg}$ of trans-resveratrol, although CRP, IL-1 $\beta$, IL-6 and IL-8 concentrations were not affected [33]. Finally, a single oral dose of $100 \mathrm{mg}$ of resveratrol and $75 \mathrm{mg}$ of total polyphenols from a muscadine grape extract suppressed the mRNA and protein expression of inflammatory proteins induced by a high-fat, high-carbohydrate meal in healthy participants [34]. Effects, however, may have been due to the muscadine grape extract. In the present study, no effects were found on plasma concentrations of fasting or postprandial inflammatory and endothelial biomarkers. Only sICAM-1 concentrations increased $120 \mathrm{~min}$ after trans-resveratrol supplementation, compared with the placebo. After $240 \mathrm{~min}$, concentrations were comparable. This effect was not observed for any of the other vascular function markers and may therefore have been due to chance, which warrants further study. In another study, sICAM-1 concentrations improved after 1-year consumption of a grape supplement including only $8 \mathrm{mg}$ of resveratrol in patients who received statins in the primary prevention of cardiovascular disease [35]. Taken together, evidence that resveratrol supplementation changes in vivo plasma concentrations of endothelial and inflammatory biomarkers, is limited. 


\section{Conclusions}

Vascular function as measured by FMD and $\mathrm{PWV}_{\mathrm{cf}}$ did not change after $150 \mathrm{mg} /$ day of trans-resveratrol supplementation for 4 weeks. Furthermore, the lack of effect on postprandial plasma glucose, plasma insulin, and serum triacylglycerol concentrations, as well as postprandial plasma endothelial and inflammatory biomarkers, extends our earlier findings [2] that $150 \mathrm{mg}$ of trans-resveratrol daily for 4 weeks had no effects on these parameters in the fasting state.

Supplementary Materials: The following are available online at www.mdpi.com/2072-6643/9/6/596/s1: Figure S1: Participants flow chart; Table S1: Composition of the test meal; Table S2: Baseline characteristics of the participants.

Acknowledgments: This study was funded by the Top Institute Food and Nutrition (TIFN), a public-private partnership on pre-competitive research in food and nutrition. Trans-resveratrol and placebo capsules were provided by DSM Nutritional Products Ltd. (Kaiseraugst, Switzerland). We would like to thank Martine Hulsbosch and Maud Beckers for their technical support and Nina Wystyrk for her dietary assistance.

Author Contributions: S.M.v.d.M., J.P. and R.P.M. designed the study; S.M.v.d.M. performed the study; S.M.v.d.M. and R.P.M. analyzed the data; S.M.v.d.M., J.P. and R.P.M. wrote the paper. All authors have read and approved the final manuscript.

Conflicts of Interest: The authors declare no conflict of interest. The founding sponsors had no role in the design of the study; in the collection, analyses, or interpretation of data; in the writing of the manuscript; or in the decision to publish the results.

\section{References}

1. Vang, O.; Ahmad, N.; Baile, C.A.; Baur, J.A.; Brown, K.; Csiszar, A.; Das, D.K.; Delmas, D.; Gottfried, C.; Lin, H.Y.; et al. What is new for an old molecule? Systematic review and recommendations on the use of resveratrol. PLoS ONE 2011, 6, e19881. [CrossRef] [PubMed]

2. Van der Made, S.M.; Plat, J.; Mensink, R.P. Resveratrol does not influence metabolic risk markers related to cardiovascular health in overweight and slightly obese subjects: A randomized, placebo-controlled crossover trial. PLoS ONE 2015, 10, e0118393. [CrossRef] [PubMed]

3. Sahebkar, A.; Serban, C.; Ursoniu, S.; Wong, N.D.; Muntner, P.; Graham, I.M.; Mikhailidis, D.P.; Rizzo, M.; Rysz, J.; Sperling, L.S.; et al. Lack of efficacy of resveratrol on C-reactive protein and selected cardiovascular risk factors-Results from a systematic review and meta-analysis of randomized controlled trials. Int. J. Cardiol. 2015, 189, 47-55. [CrossRef] [PubMed]

4. Thazhath, S.S.; Wu, T.; Bound, M.J.; Checklin, H.L.; Standfield, S.; Jones, K.L.; Horowitz, M.; Rayner, C.K. Administration of resveratrol for $5 \mathrm{wk}$ has no effect on glucagon-like peptide 1 secretion, gastric emptying, or glycemic control in type 2 diabetes: A randomized controlled trial. Am. J. Clin. Nutr. 2016, 103, 66-70. [CrossRef] [PubMed]

5. Wallerath, T.; Deckert, G.; Ternes, T.; Anderson, H.; Li, H.; Witte, K.; Forstermann, U. Resveratrol, a polyphenolic phytoalexin present in red wine, enhances expression and activity of endothelial nitric oxide synthase. Circulation 2002, 106, 1652-1658. [CrossRef] [PubMed]

6. Takizawa, Y.; Kosuge, Y.; Awaji, H.; Tamura, E.; Takai, A.; Yanai, T.; Yamamoto, R.; Kokame, K.; Miyata, T.; Nakata, R.; et al. Up-regulation of endothelial nitric oxide synthase (eNOS), silent mating type information regulation 2 homologue 1 (SIRT1) and autophagy-related genes by repeated treatments with resveratrol in human umbilical vein endothelial cells. Br. J. Nutr. 2013, 110, 2150-2155. [CrossRef] [PubMed]

7. Corretti, M.C.; Anderson, T.J.; Benjamin, E.J.; Celermajer, D.; Charbonneau, F.; Creager, M.A.; Deanfield, J.; Drexler, H.; Gerhard-Herman, M.; Herrington, D.; et al. Guidelines for the ultrasound assessment of endothelial-dependent flow-mediated vasodilation of the brachial artery: A report of the International Brachial Artery Reactivity Task Force. J. Am. Coll. Cardiol. 2002, 39, 257-265. [CrossRef]

8. Wong, R.H.; Howe, P.R.; Buckley, J.D.; Coates, A.M.; Kunz, I.; Berry, N.M. Acute resveratrol supplementation improves flow-mediated dilatation in overweight/obese individuals with mildly elevated blood pressure. Nutr. Metab. Cardiovasc. Dis. 2011, 21, 851-856. [CrossRef] [PubMed]

9. Wong, R.H.; Berry, N.M.; Coates, A.M.; Buckley, J.D.; Bryan, J.; Kunz, I.; Howe, P.R. Chronic resveratrol consumption improves brachial flow-mediated dilatation in healthy obese adults. J. Hypertens. 2013, 31, 1819-1827. [CrossRef] [PubMed] 
10. Magyar, K.; Halmosi, R.; Palfi, A.; Feher, G.; Czopf, L.; Fulop, A.; Battyany, I.; Sumegi, B.; Toth, K.; Szabados, E. Cardioprotection by resveratrol: A human clinical trial in patients with stable coronary artery disease. Clin. Hemorheol. Microcirc. 2012, 50, 179-187. [PubMed]

11. Gaenzer, H.; Sturm, W.; Neumayr, G.; Kirchmair, R.; Ebenbichler, C.; Ritsch, A.; Foger, B.; Weiss, G.; Patsch, J.R. Pronounced postprandial lipemia impairs endothelium-dependent dilation of the brachial artery in men. Cardiovasc. Res. 2001, 52, 509-516. [CrossRef]

12. Vogel, R.A.; Corretti, M.C.; Plotnick, G.D. Effect of a single high-fat meal on endothelial function in healthy subjects. Am. J. Cardiol. 1997, 79, 350-354. [CrossRef]

13. Devaraj, S.; Wang-Polagruto, J.; Polagruto, J.; Keen, C.L.; Jialal, I. High-fat, energy-dense, fast-food-style breakfast results in an increase in oxidative stress in metabolic syndrome. Metabolism 2008, 57, 867-870. [CrossRef] [PubMed]

14. Ghanim, H.; Abuaysheh, S.; Sia, C.L.; Korzeniewski, K.; Chaudhuri, A.; Fernandez-Real, J.M.; Dandona, P. Increase in plasma endotoxin concentrations and the expression of Toll-like receptors and suppressor of cytokine signaling-3 in mononuclear cells after a high-fat, high-carbohydrate meal: Implications for insulin resistance. Diabetes Care 2009, 32, 2281-2287. [CrossRef] [PubMed]

15. Assmann, G.; Schulte, H.; von Eckardstein, A.; Huang, Y. High-density lipoprotein cholesterol as a predictor of coronary heart disease risk. The PROCAM experience and pathophysiological implications for reverse cholesterol transport. Atherosclerosis 1996, 124, S11-S20. [CrossRef]

16. Van Bortel, L.M.; Laurent, S.; Boutouyrie, P.; Chowienczyk, P.; Cruickshank, J.K.; De Backer, T.; Filipovsky, J.; Huybrechts, S.; Mattace-Raso, F.U.; Protogerou, A.D. Expert consensus document on the measurement of aortic stiffness in daily practice using carotid-femoral pulse wave velocity. J. Hypertens. 2012, 30, 445-448. [CrossRef] [PubMed]

17. Joris, P.J.; Mensink, R.P. Beetroot juice improves in overweight and slightly obese men postprandial endothelial function after consumption of a mixed meal. Atherosclerosis 2013, 231, 78-83. [CrossRef] [PubMed]

18. Matthews, J.N.; Altman, D.G.; Campbell, M.J.; Royston, P. Analysis of serial measurements in medical research. BMJ 1990, 300, 230-235. [CrossRef] [PubMed]

19. Pocock, S.J. Clinical Trials: A Practical Approach; John Wiley and Sons: Chichester, UK, 1987.

20. Bradamante, S.; Barenghi, L.; Piccinini, F.; Bertelli, A.A.; De Jonge, R.; Beemster, P.; De Jong, J.W. Resveratrol provides late-phase cardioprotection by means of a nitric oxide- and adenosine-mediated mechanism. Eur. J. Pharmacol. 2003, 465, 115-123. [CrossRef]

21. Zhang, H.; Zhang, J.; Ungvari, Z.; Zhang, C. Resveratrol improves endothelial function. Role of TNF (alpha) and vascular oxidative stress. Arterioscler. Thromb. Vasc. Biol. 2009, 29, 1164-1171. [CrossRef] [PubMed]

22. Rotches-Ribalta, M.; Andres-Lacueva, C.; Estruch, R.; Escribano, E.; Urpi-Sarda, M. Pharmacokinetics of resveratrol metabolic profile in healthy humans after moderate consumption of red wine and grape extract tablets. Pharmacol. Res. 2012, 66, 375-382. [CrossRef] [PubMed]

23. Bae, J.H.; Schwemmer, M.; Lee, I.K.; Lee, H.J.; Park, K.R.; Kim, K.Y.; Bassenge, E. Postprandial hypertriglyceridemia-induced endothelial dysfunction in healthy subjects is independent of lipid oxidation. Int. J. Cardiol. 2003, 87, 259-267. [CrossRef]

24. Westphal, S.; Taneva, E.; Kastner, S.; Martens-Lobenhoffer, J.; Bode-Boger, S.; Kropf, S.; Dierkes, J.; Luley, C. Endothelial dysfunction induced by postprandial lipemia is neutralized by addition of proteins to the fatty meal. Atherosclerosis 2006, 185, 313-319. [CrossRef] [PubMed]

25. Johnson, B.D.; Padilla, J.; Harris, R.A.; Wallace, J.P. Vascular consequences of a high-fat meal in physically active and inactive adults. Appl. Physiol. Nutr. Metab. 2011, 36, 368-375. [CrossRef] [PubMed]

26. Westphal, S.; Luley, C. Flavanol-rich cocoa ameliorates lipemia-induced endothelial dysfunction. Heart Vessel. 2011, 26, 511-515. [CrossRef] [PubMed]

27. Lynn, A.; Hamadeh, H.; Leung, W.C.; Russell, J.M.; Barker, M.E. Effects of pomegranate juice supplementation on pulse wave velocity and blood pressure in healthy young and middle-aged men and women. Plant Foods. Hum. Nutr. 2012, 67, 309-314. [CrossRef] [PubMed]

28. West, S.G.; McIntyre, M.D.; Piotrowski, M.J.; Poupin, N.; Miller, D.L.; Preston, A.G.; Wagner, P.; Groves, L.F.; Skulas-Ray, A.C. Effects of dark chocolate and cocoa consumption on endothelial function and arterial stiffness in overweight adults. Br. J. Nutr. 2014, 111, 653-661. [CrossRef] [PubMed] 
29. Csiszar, A.; Smith, K.; Labinskyy, N.; Orosz, Z.; Rivera, A.; Ungvari, Z. Resveratrol attenuates TNF-alpha-induced activation of coronary arterial endothelial cells: Role of NF-kappaB inhibition. Am. J. Physiol. Heart Circ. Physiol. 2006, 291, H1694-H1699. [CrossRef] [PubMed]

30. Wung, B.S.; Hsu, M.C.; Wu, C.C.; Hsieh, C.W. Resveratrol suppresses IL-6-induced ICAM-1 gene expression in endothelial cells: Effects on the inhibition of STAT3 phosphorylation. Life Sci. 2005, 78, 389-397. [CrossRef] [PubMed]

31. Ferrero, M.E.; Bertelli, A.E.; Fulgenzi, A.; Pellegatta, F.; Corsi, M.M.; Bonfrate, M.; Ferrara, F.; De Caterina, R.; Giovannini, L.; Bertelli, A. Activity in vitro of resveratrol on granulocyte and monocyte adhesion to endothelium. Am. J. Clin. Nutr. 1998, 68, 1208-1214. [PubMed]

32. Agarwal, B.; Campen, M.J.; Channell, M.M.; Wherry, S.J.; Varamini, B.; Davis, J.G.; Baur, J.A.; Smoliga, J.M. Resveratrol for primary prevention of atherosclerosis: Clinical trial evidence for improved gene expression in vascular endothelium. Int. J. Cardiol. 2013, 166, 246-248. [CrossRef] [PubMed]

33. Timmers, S.; Konings, E.; Bilet, L.; Houtkooper, R.H.; van de Weijer, T.; Goossens, G.H.; Hoeks, J.; van der Krieken, S.; Ryu, D.; Kersten, S.; et al. Calorie restriction-like effects of 30 days of resveratrol supplementation on energy metabolism and metabolic profile in obese humans. Cell Metab. 2011, 14, 612-622. [CrossRef] [PubMed]

34. Ghanim, H.; Sia, C.L.; Korzeniewski, K.; Lohano, T.; Abuaysheh, S.; Marumganti, A.; Chaudhuri, A.; Dandona, P. A resveratrol and polyphenol preparation suppresses oxidative and inflammatory stress response to a high-fat, high-carbohydrate meal. J. Clin. Endocrinol. Metab. 2011, 96, 1409-1414. [CrossRef] [PubMed]

35. Tome-Carneiro, J.; Gonzalvez, M.; Larrosa, M.; Yanez-Gascon, M.J.; Garcia-Almagro, F.J.; Ruiz-Ros, J.A.; Garcia-Conesa, M.T.; Tomas-Barberan, F.A.; Espin, J.C. One-year consumption of a grape nutraceutical containing resveratrol improves the inflammatory and fibrinolytic status of patients in primary prevention of cardiovascular disease. Am. J. Cardiol. 2012, 110, 356-363. [CrossRef] [PubMed] 